\title{
Kinolin Temelli Yeni Antikanser Ajanlar
}

\author{
${ }^{* 1}$ Salih Ökten \\ ${ }^{* 1}$ Eğitim Fakültesi, Matematik ve Fen Bilimleri Eğitimi Bölümü, Kırıkkale Üniversitesi, Türkiye
}

\begin{abstract}
Quinoline is the main skeleton of many natural and pharmacologically active compounds that exhibit a broad spectrum of biological activity. We have now discovered new synthetic strategies for the synthesis of 6-bromo-, 6,8-dibromo- and 3,6,8-tribromoquinolines by the bromination reaction of substituted or unsubstituted 1,2,3,4-tetrahydroquinoline. Convenient synthesis routes of 6,8-disubstituted quinoline derivatives from brominated quinolines by metal-bromine exchange reactions and precursor compounds for disubstituted quinolines of brominated products have been reported. Subsequently, 6,8dibromoquinoline was converted to phenyl, cyano, methoxy and hydroxy derivatives by coupling and substitution reactions. Derivatives prepared by this strategy showed specific anticancer activities. In accordance with the structure activity studies, it was determined that quinoline derivatives having phenyl, cyano, nitro, methoxy groups showed effective inhibition against colon, cervical, lung, breast cancer cell lines. In order to determine cytotoxicities of synthesized derivatives LDH cytotoxicity assay were examined. In summary, 6,8-dibromo-1,2,3,4-tetrahydroquinoline, 8-bromo-6-cyanoquinoline, 6,8diphenylquinoline derivatives can be promising anticancer agent candidates.
\end{abstract}

Key words: Quinoline, anticancer effect, tetrahydroquinoline, cyanoquinoline, bromoquinoline

\section{Özet}

Kinolin, geniş bir spektrumda biyolojik aktivite sergileyen birçok doğal ve farmakolojik açıdan aktif bileşiğin ana iskeletini oluşturur. Günümüzde, sübstitüe edilmiş veya sübstitüe edilmemiş 1,2,3,4tetrahidrokinolinin bromlama reaksiyonuyla 6-bromo-, 6,8-dibromo- ve 3,6,8-tribromokinolinlerin sentezi için yeni bir sentetik stratejiler keşfedildi. Metal-brom değişimi reaksiyonlarıyla bromlu kinolinlerden 6,8-disübstitüe edilmiş kinolin türevlerinin uygun sentez yollarını ve bromlu ürünlerin disübstitüe kinolinler için öncü bileşikler rapor edildi. Bu çalışmaların akabinde, 6,8-dibromokinolin, kenetleme ve yer değiştirme reaksiyonları ile fenil, siyano, metoksi ve hidroksi türevlerine dönüştürüldü. $\mathrm{Bu}$ strateji ile sentezlenen türevler, spesifik antikanser aktiviteleri gösterdi. Yapı aktivite çalışmalarına uygun olarak, fenil, siyano, nitro, metoksi gruplarına sahip kinolin türevlerinin kolon, servikal, akciğer, göğüs kanser hücre hatlarına karşı etkili bir inhibisyon gösterdiği tespit edilmiştir. Sentezlenen türevlerin sitotoksisitesini belirlemek için LDH sitotoksisite testleri incelenmiştir. Özetle, 5,7-dibromo-8hidroksikinolin, 6,8-dibromo-1,2,3,4-tetrahidrokinolin, 8-bromo-6-siyanokinolin, 6,8-difenilkinolin türevleri umut verici antikanser ajan adayı olabilir.

Anahtar Kelimeler: Kinolin, antikanser etki, tetrahidrokinolin, siyanokinolin, bromokinolin

\section{Giriş}

Kinolin çekirdeği, geniş bir biyolojik aktivite spektrumu sergileyen birçok doğal ve farmakolojik açıdan aktif bileşiklerin ana iskeletini oluşturur [1-4]. Tıp, bioorganik, endüstriyel ve sentetik organik kimya alanlarında önemli uygulamalara sahip olan kinolin türevlerinin sentezi için etkili

*Corresponding author: Address: ${ }^{1}$ Eğitim Fakültesi, Matematik ve Fen Bilimleri Eğitimi Bölümü, Kırıkkale Üniversitesi, TÜRKIYE. E-posta adresi: salihokten@kku.edu.tr, Tel: +903183574242/1394 
yöntemlerin geliştirilmesine büyük ilgi duyulmaktadır. Bununla birlikte, kinolin çekirdeğinin polibromlanması / sübstitüe edilmesi için uygun prosedürlerin bulunmamasından dolayı, bu alanı sınırlamıştır.

En yaygın stratejiler, $N$-fonksiyonalize benzen veya sikloheksanın halkalaşma reaksiyonlarıdır [58]. Ancak, araştırma grubumuz kinolin çekirdeğinin çoklu işlevlendirilmesine dayanan farklı ve uygun metotlar geliştirdik. Geliştirdiğimiz stratejiler klasik sentez yöntemlerinden tamamiyle farklıdır. 1,2,3,4-tetrahidrokinolin gibi başlangıç maddeleri ticari olarak temin edilebilir ve çok ucuzdur. Tepkimeler çok basit ve alan seçicidir.

Son zamanlarda, kinolin halkasının C-8 konumunda, metoksi ve hidroksi grupları içeren 8sübstitüe edilmiş kinolin türevlerinin sentezini ve insan adenokarsinomuna (HT29), insan rahim ağzı kanseri (HeLa) ve sıçan glioblastoma (C6) hücrelerine karşı güçlü sitotoksik etkileri rapor edildi. 8-Sübstitüe kinolin türevlerinin arasında, 5,7-dibromo-8-hidroksikinolin, 7-bromo-8hidroksi-, 7-siyano-8-hidroksi- ve 5,7-disiyano-8-hidroksikinolinler C6, HeLa ve HT29 hücre hatlarına karşı apoptozu indükleyerek rekombinant insan DNA topoizomeraz I enzimini inhibe ettiği belirlendi [9]. Grubumuz tarafından antikanser ajanlarının geliştirilmesi üzerine devam araştırmalarda, metoksi, siyano, nitro, $N$-oksit ve fenil gruplarının, kanser hücre hatlarında antiproliferatif aktivitelere etkisinin hakkında daha fazla bilgi edinmek için bu grupları ihtiva eden yeni bileşiklerine sentezlendi. Bu çalışmada, bazı farklı di ve mono bromo, siyano ve fenil sübstitüe kinolin ve tetrahidrokinolin türevlerinin MCF7 (insan gögüs adenokarsinomu), HeLa (insan serviks adenokarsinomu) ve HT29 (insan kolorektal adenokarsinomu) kanser hücresi hatlarına karş1 MTT kiti ile antiproliferatif etkileri ve LDH kiti ile sitotoksik potansiyellerinin belirlenmesini amaçlanmıştır.

\section{Materyal ve Metod}

\subsection{Sübstitüe kinolinlerin sentezi}

Bu çalışma, literatürde sentezlerini rapor ettiğimiz sübstitüe kinolin türevleri ile yürütülmüştür [10$15]$.

\subsection{Antikanser Çalış̧aları}

In vitro antikanser aktivite testleri Gaziosmanpaşa Üniversitesi Moleküler Biyoloji Bölümü tarafindan HT29 (insan kolorektal adenokarsinomu), HeLa (insan serviks adenokarsinomu) ve MCF7 (insan göğüs adenokarsinomu) kanser hücre hatları kullanılarak yapılmıştır. Bu kanser hücresi hatları, Amerikan Tipi Kültür Koleksiyonundan (Manassas, VA) elde edildi ve her ikisi de $\% 5(\mathrm{~h} / \mathrm{h})$ fetal sığır serumu ile takviye edilmiş Dulbecco modifiye Eagle Ortamı (DMEM; Sigma, Darmstadt, Almanya) içinde kültürlendi; penisilin $(100 \mathrm{IU} / \mathrm{mL})$ ve streptomisin $(100 \mu \mathrm{g} / \mathrm{mL})$. Hücre kültürü için ayrıntıll prosedür önceki makalelerde bildirilmiştir $[9,24,25]$. Kinolin bileşiklerinin antiproliferatif aktiviteleri, in vitro SRB [16] ve bromodeoksiüridin (BrdU) hücre proliferasyonu ELISA (BCPE) yöntemleri kullanılarak önceki prosedürlere göre $[9,17,18]$ belirlenmiştir. Sitotoksisite, LDH yayılması ile belirlenmiştir. 


\section{3. İstatiksel Analiz}

İstatistiksel analiz için, Windows bilgisayar programı için SPSS (Sosyal Bilimler için İstatistik Paketi), standart sapma, P değeri, ortalamalar, tek yönlü varyans analizi (ANOVA) ve ardından tukey testi uygulanmıştır.

\section{Bulgular}

İlk olarak, bir dizi bromino tetrahidrokinolinler ve aromatik türevleri, tetrahidrokinolin ve 8sübstitüe edilmiş hidroksi, metoksi ve amin kinolinler moleküler brom ile muamelesi ile sentezlendi. Daha sonra, bromokinolinler, tek ürün olarak birkaç kromatografik yöntem kullanılarak izole edildi ve yapıları, NMR, IR ve kütle spektrumları ile karakterize edildi $[10,11$, $14,15]$. Bir sonraki adımda, bromlu tetrahidrokinolin ve bromo kinolin türevleri, metal destekli yer değiştirme reaksiyonlarıyla siyano- [15] türevlerine dönüş̧ürüldü ve Suzuki-Miyura çapraz bağlama reaksiyonları [19] tarafından fenil kinolin elde edildi (Şekil 1).
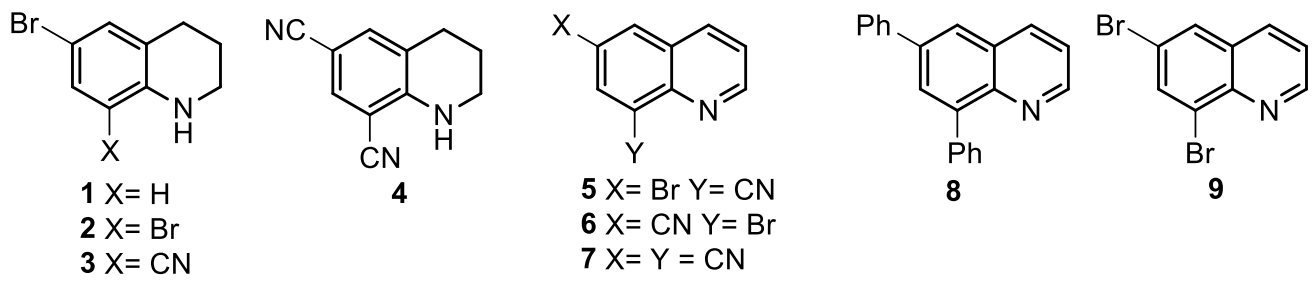

Şekil 1. Sübstitüe kinolin türevleri

Birçok antikanser ilaç adayı, ciddi yan etkileri, ilaçlara duyarlılık kaybı ve birçok kanser türü için sınırlı kullanım nedeniyle piyasadan çekilmiştir. Kinolin türevlerinin antikanser aktiviteleri birçok çalışmada rapor edilmiştir. Son çalışmalarımızda $[9,10,20]$, 6,8-dibromo-1,2,3,4tetrahidrokinolin, 5,7-dibromo-8-hidroksikinolin, 6-bromo-8-siyano-1,2,3,4-tetrahidrokinolin ve nitratlanmış 3,6,8-tribromokinolin'in antiproliferatif aktiviteleri Sulfo-Rhodamine-B boyası (SRB) ve BrdU Hücre Proliferasyonu ELISA (BCPE) analizleri kullanılarak HeLa, HT29 ve MCF7 hücre hatlarına karşı rapor edildi. Bu çalışma, sübstitüe kinolin türevleri (Tablo 1), araştırma grubumuz tarafindan rapor edilen prosedürlere [10-15] hazırlanan ve bunların HeLa, HT29, ve MCF7 hücre hatlarına karşı antikanser etkileri ve sitotoksisitelerini rapor etmektedir. Bileşiklerin $\mathrm{IC}_{50}$ değerleri incelendiğinde, test edilen bileşiklerin, test edilen tüm hücre hatlarına karşı seçici antitümör özelliklerine neden olduğu belirlenmiştir (Tablo 1).

Tablo 1. Bileşiklerin HeLa, HT29 ve MCF7 hücre hatlarında $\mathrm{IC}_{50}(\mu \mathrm{g} / \mathrm{mL})$ değerleri

\begin{tabular}{lrrr}
\hline Compounds & HeLa & \multicolumn{1}{c}{ HT29 } & \multicolumn{1}{c}{ MCF7 } \\
\hline $\mathbf{I}$ & 42.5 & 31.8 & 29.8 \\
$\mathbf{2}$ & 30.7 & 27.9 & 39.3 \\
$\mathbf{4}$ & $>1000$ & 98.1 & $>1000$ \\
$\mathbf{5}$ & $>1000$ & 465.9 & 683.6 \\
$\mathbf{6}$ & 40.3 & 31.5 & 40.6
\end{tabular}




\begin{tabular}{lrrr}
7 & $>1000$ & 894.5 & $>1000$ \\
$\mathbf{8}$ & 31.8 & 42.5 & 38.4 \\
$\mathbf{9}$ & 295.4 & $>1000$ & 309.2 \\
Cisplatin & 50.7 & 46.4 & 60.8 \\
\hline
\end{tabular}

Hücrelerdeki bileşiklerin sitotoksisiteleri, dolaylı olarak membran hasarı gösteren LDH kiti ile test edildi. Sitoplazmik LDH aktivitesinin ölçüm sonuçları bu bileşikler için değerlendirildiğinde, MCF7 hücreleri için 4, 5 ve 9; HeLa hücreleri için 5, 7 ve 9 ve HT29 hücreleri için 5 ve $\mathbf{7}$ IC 50 konsantrasyonlarında yaklaşık \%10 - \%30 membran hasarına neden olmuştur (Şekil 1). Bileşikler bu değerlendirme için kontrolle (Cisplatin) karşılaştırılırsa, yukarıda belirtilen moleküllerin sitoksisitesi Cisplatin'in sitotoksisite değerlerine yakındır (Şekil 2). Bu nedenle, ileri farmakolojik analizler için uygun olabilirler.

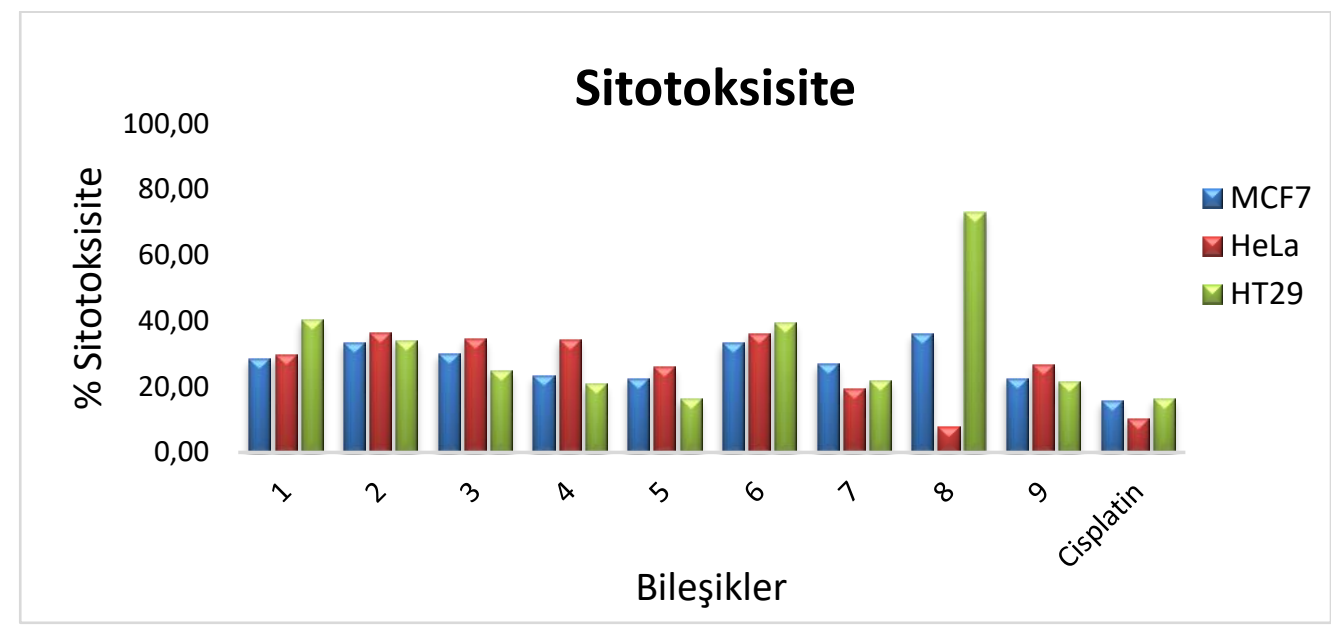

Şekil 2. Sübstitüe kinolin türevlerinin sitotoksisitesi

\section{Tartışma}

Kinolin halkasındaki sübstitüentlerin, antiproliferatif etkilerinin belirlenmesi, bileşik $\mathbf{7}$ ve $\mathbf{1 0}$ 'daki C-6 ve C-8 pozisyonlarındaki bromin ve siyano gruplarının varlığının kanser hücre hatlarının çoğalmasını engellemediğini gösterdi. Bileşik 9'un C-6 ve C-8 konumlarındaki brom, test edilen hücre hatlarına karşı antiproliferatif aktiviteye sahip olmamasına rağmen, bileşik 6'nın C-6 konumunda bulunan siyano grubu, test edilen kanser hücrelerinin hepsine karş1 prolisferasyonlarının önemli ölçüde inhibe etme potansiyellerine sahip olmasına yol açmıştır. Bununla birlikte, bileşik 5'te C-8'deki nitril grubunun varlığı, test edilmiş kanser hücre hatlarına karşı inhibisyon göstermemiştir. Bunlara ilaveten, C-6 ve C-8 konumlarında 1,2,3,4tetrahidrokinolin bromlanması, yani 1 ve 2 bileşikleri, $\mathrm{IC}_{50}$ aralığında 27.9 ve $42.5 \mathrm{~g} / \mathrm{mL} \mathrm{MCF}$, HT29 ve HeLa hücre hatlarına karşı antiproliferatif aktivitelerde artış göstermiştir. Bununla birlikte, 6,8-dibromotetrahidrokinolinin güçlü antiproliferatif aktivitesi, C-6 ve/veya C-8 konumları siyano grupları değiştirilmesi durumunda (3 ve 4 bileşiklerinde) test edilen kanser hücre hatlarında önemli ölçüde azalmıştır. Bileşik 9'un C-6 ve C-8 konumlarındaki bromlar, fenil grupları ile yer değiştirdiğinde (Bileşik 8) antiproliferatif aktivite önemli ölçüde arttığı gözlemlenmiştir. 


\section{Sonuç}

Bileşiklerin $\mathrm{IC}_{50}$ değerleri incelendiğinde, 8-bromo-6-siyanokinolin (6) ( $\mathrm{IC}_{50}$ değerleri 31.5 ve 40.6 $\mu \mathrm{g} / \mathrm{mL}$ arasında), 6.8-dibromotetrahidrokinolin (2) (IC 50 değerleri 27.9 ve $39.3 \mu \mathrm{g} / \mathrm{mL}$ arasında) ve 6,8-difenilkinolin (8) ( $\mathrm{IC}_{50}$ değerleri $31.8 \mathrm{ve} 42.5 \mu \mathrm{g} / \mathrm{mL}$ arasında) test edilen tüm hücre hatlarına karşı çok güçlü antitümör etkilere neden olduğunu belirlenmiştir. $\mathrm{Bu}$ sonuç, bu üç bileşiğin antikanser ajan adayı olma potansiyellerinin olduğunu ve ileri farmakolojik çalışmalarda kullanılabileceklerini göstermektedir.

\section{Teşekkür}

Bu çalışma Kırıkkale Üniversitesi Bilimsel Araştırma Projeleri Koordinasyon Birimi tarafından (Proje no: 2017/067) desteklenmiştir.

\section{Kaynaklar}

1. Srivastava SK, Chauhan PMS, Bhaduri AP, Fatima N, Chatterjee R. Quinolones: Novel Probes in Antifilarial Chemotheraphy, J Med Chem 2000; 43:2275-9.

2. Zhang N, Wu B, Powell D, Wissner A, Floyd MB, Kovacs ED, Toral-Barza L, Kohler C. Synthesis and structure-activity relationships of 3-cyano-4-(phenoxyanilino)quinolines as MEK (MAPKK) inhibitors. Bioorg Med Chem Lett 2000; 10:2825-8.

3. Muscia GC, Bollini M, Carnevale JP, Bruno AM, Asis SE. Microwave-assisted Friedländer synthesis of quinolines derivatives as potential antiparasitic agents. Tetrahedron Lett 2006; 47:8811-5.

4. Solomon VR, Lee H. Chloroquine and its analogs: A new promise of an old drug for effective and safe cancer therapies. Eur J Pharmacol 2009; 625:220-33.

5. Jones G. The Chemistry of Heterocyclic Compounds. 3rd ed. London: John Willey and Sons; 1977.

6. Manske RHF, Kukla M. The Skraup Synthesis of Quinolines. Org React 1953;7:59-164.

7. Cheng CC, Yan SJ. The Friedländer Synthesis of Quinoline. Org React 1982; 28:37-138.

8. Bergstrom FW. Heterocyclic Nitrogen Compounds. Part IIA. Hexacyclic Compounds: Pyridine, Quinoline, and Isoquinoline. Chem Rev 1944; 35:77-277.

9. Ökten S, Çakmak O, Tekin Ş, Köprülü TK. A SAR Study: Evaluation of bromo derivatives of 8-substituted quinolines as novel anticancer agents. Lett Drug Des Discov 2017; 14:1415. 
10. Ökten S, Çakmak O, Erenler R, Yüce Ö, Tekin Ş. Simple and Convenient Preparation of Novel 6,8-disubstituted Quinoline Derivatives and Their Promising Anticancer Activities. Turk J Chem 2013; 37: 896.

11. Şahin A, Çakmak O, Demirtaş I, Ökten S, Tutar A. Efficent and Selective Synthesis of Quinoline Derivatives. Tetrahedron 2008; 64: 10068-74.

12. Çelik İ, Akkurt M, Çakmak O, Ökten S, Garcia-Granda S. 6,8-Dibromoquinoline. Acta Crystallogr Sect E. 2010; E66:02997-8.

13. Çelik İ, Akkurt M, Ökten S, Çakmak O, Garcia-Granda S. 3,6,8-Tribromoquinoline. Acta Crystallogr Sect E. 2010; E66:o3133

14. Ökten S, Eyigün D, Çakmak O. Synthesis of Brominated Quinolines, Sigma J Eng Nat Sci $2015 ; 33: 8-15$.

15. Ökten S, Çakmak O. Synthesis of Novel Cyano Quinoline Derivatives, Tetrahedron Letters 2015; 56: 5337-40.

16. Skehan P, Storeng R, Scudiero D, Monks A, Mcmahon J, Vistica D, Warren JT, Bokesch H, Kenney S, Boyd MR. New colorimetric cytotoxicity assay for anticancer-drug screening. J Nat Cancer Inst 1990; 82:1107-12.

17. Ökten S, Çakmak O, Tekin Ş, Köprülü TK. Yapı Aktivite İlişkisi (SAR): Bromlanmış 8hidroksikinolin ve ftalonitril türevlerinin çeşitli kanser hücre hatları üzerine antiproliferatif aktivitelerinin incelenmesi. SAÜ Fen Bil Der 2017; 21:1300-6.

18. Köprülü TK, Ökten S, Tekin Ş, Çakmak O. Biological evaluation of some novel quinolines with different functional groups as anticancer agents. J Biochem Mol Toxicol 2019; 33:e22260.

19. Ökten S. Synthesis of aryl substituted quinolines and tetrahydroquinolines through SuzukiMiyaura coupling reactions. J Chem Res 2019; 43:274-80.

20. Ökten S, Çakmak O, Tekin Ş. The SAR study of 6,8-disubstituted quinoline derivatives as anticancer agents. Turk J Clin Lab 2017; 8:152-9. 